\title{
Kanaima Distant, 1909: descrição de uma nova espécie (Hemiptera, Auchenorrhyncha, Cercopidae, Tomaspidinae) ${ }^{1}$
}

\author{
Juliane Franzen Stancik ${ }^{2}$ \\ Rodney Ramiro Cavichioli ${ }^{3,4}$
}

\begin{abstract}
Kanaima Distant, 1909: description of a new species (Hemiptera, Auchenorrhyncha, Cercopidae, Tomaspidinae). A new species, Kanaima dubia, is described from São José dos Pinhais, Paraná, Brazil. It is similar, in general aspect, to Kanaima fluvialis (Lallemand, 1924).
\end{abstract}

KeYwords. Auchenorrhyncha; Cercopidae; Kanaima; new species; Tomaspidinae.

\section{INTRODUÇÃO}

Distant (1909) descreveu Kanaima, designando como espécie-tipo Tomaspis katzensteini [sic] Berg, 1879. BerG (1879) ao descrever T. katzensteinii, referiu-se apenas à sua distribuição geográfica na Argentina. FenNAH (1968), em sua revisão das tribos Ischinorrhinini e Tomaspidini, procurou caracterizar os gêneros com base nas estruturas da cabeça, dos tarsos das pernas posteriores e da genitália dos machos. Incluiu no gênero Kanaima mais duas espécies: Monecphora fluvialis Lallemand, 1924, com duas variedades, e Monecphora radiata Walker, 1851. FeNNAH (1979) complementou sua revisão de 1968 dos gêneros de Cercopidae do Novo Mundo e incluiu Monecphora vittata Walker, 1851 em Kanaima. WALKER, (1851) quando descreveu M. radiata e $M$. vittata, mencionou apenas as suas localidades-tipo, Venezuela e América do Sul, respectivamente.

Estudando os espécimes coletados na região de São José dos Pinhais, Paraná, Brasil, por R.R. Cavichioli, sobre uma espécie de Eryngium (Apiaceae), concluiu-se que se tratava de uma espécie nova que poderia ser enquadrada em Kanaima ou em Mahanarva Distant, 1909. Duas espécies (K. fluvialis, K. katzensteinii) já haviam sido coletadas em Eryngium, porém em uma espécie diferente daquela na qual ocorre a espécie nova.

Na espécie de Eryngium em que ocorrem $K$. fluvialis e $K$. katzensteinii, também são registradas as seguintes espécies de Cicadellinae: Balacha melanocephala (Signoret, 1854), B. similis Cavichioli \& Sakakibara, 1988, B. decorata Cavichioli \& Sakakibara, 1988 e Ochrostacta diadema (Burmeister, 1835), todas com padrão enegrescido com faixas amarelo-pálidas. Já na espécie de Eryngium em que ocorre a espécie nova aqui proposta, registra-se a ocorrência de duas espécies de Balacha descritas por CAVICHIOLI \& SAKAKIBARA (1988), B. rubripennis e B. lepida, ambas com coloração avermelhada.

Para a definição do gênero foram utilizadas, para comparação, duas espécies de Kanaima, K. fluvialis e $K$. katzensteinii, e duas espécies de Mahanarva, M. fimbriolata Stal, 1854 e M. posticata Stal, 1855. Após análise do material, propõe-se que a espécie nova seja incluída em Kanaima, porém com ressalvas.

O material utilizado está depositado na Coleção de Entomologia "Pe. Jesus Santiago Moure" do Departamento de Zoologia / Universidade Federal do Paraná (DZUP).

A terminologia adotada para as regiões da cabeça foi aquela de Hamilton (1981); para as estruturas de genitália do macho foi utilizada a terminologia de FENNAH (1968), e para as da fêmea, a de Nielson (1965); para as demais estruturas foi utilizada a de SNODGRASS (1935).

\section{Kanaima dubia sp. nov.}

(Figs. 1-13)

Material-tipo. Holótipo macho. BRASIL. Paraná. São José

\footnotetext{
1. Contribuição nº 1308 do Departamento de Zoologia, Universidade Federal do Paraná.

2. Bolsista PIBIC/CNPq/UFPR. Endereço eletrônico: jstancik@bol.com.br

3. Departamento de Zoologia, Universidade Federal do Paraná. Caixa Postal 19020, 81531-990 Curitiba - PR, Brasil.

Endereço eletrônico: cavich@bio.ufpr.br

4. Bolsista CNPq 301527/85-7.
} 
dos Pinhais, 22.XI.1985 (R. R. Cavichioli) [DZUP]. Parátipos. BRASIL. Paraná. São José dos Pinhais, 22.XI.1985 (R. R. Cavichioli), 12 machos e 14 fêmeas [DZUP]. Da série de parátipos, serão depositados um macho e uma fêmea no The Natural History Museum, Londres.

Medidas (em mm). Holótipo. Comprimento mediano da cabeça: 1,52; largura trans-ocular: 3,20; largura interocular: 1,96; largura ocelo-ocular: 0,64 ; largura interocelar: 0,28 ; comprimento ocelo-margem posterior da cabeça: 0,28 ; comprimento mediano do pronoto: 2,80; largura trans-umeral: 5,08; comprimento mediano do escutelo: 2,40; largura máxima do escutelo: 2,40; comprimento total: 14,00 .

Descrição. Holótipo macho. Cabeça (Fig. 1), em vista dorsal, subtriangular, duas vezes mais larga que longa, amplamente coberta por microcerdas decumbentes. Vértice levemente elevado nas regiões entre os olhos e os ocelos, formando uma evidente carena longitudinal mediana que segue até o tilo; ocelos proeminentes, situados atrás da linha imaginária que tangencia os bordos anteriores dos olhos; distância entre ocelos aproximadamente igual à distância entre ocelos e margem posterior da cabeça, e à metade da distância entre ocelo e olho; olhos proeminentes e transversos. Lóbulos suprantenais, em vista dorsal, proeminentes, carenados e levemente arqueados; em vista lateral, carenados e lineares; antenas conspícuas, em vista lateral, com escapo curto e cilíndrico, pedicelo cilíndrico, de comprimento aproximadamente igual a duas vezes o seu diâmetro basal; base do flagelo pequena, ovóide, e flagelo alongado com comprimento aproximadamente quatro vezes o do pedicelo; arista implantada no mesmo plano do flagelo, com comprimento aproximadamente igual ao da base do flagelo. Fronte, em vista frontal, ovóide, inflada, coberta com microcerdas, com impressões musculares nítidas e com uma carena mediana evidente, contínua àquela do tilo, em vista lateral (Fig. 2), arqueada; sutura epistomal completa. Clípeo, em vista frontal, triangular, coberto por microcerdas; margem anterior arredondada (Fig. 2), contínua à fronte. Rostro com artículo apical mais curto que o precedente, atingindo a metade das coxas mesotorácicas, com margens laterais cobertas por microcerdas.

Pronoto hexagonal (Fig. 1), com comprimento mediano igual à metade da largura entre os úmeros, convexo, superfície dorsal densamente pontuada e coberta por microcerdas; margem anterior retilínea, as látero-anteriores convergentes anteriormente e as látero-posteriores levemente arqueadas para dentro, e a posterior com uma forte reentrância mediana. Escutelo triangular (Fig.1), quase tão largo basalmente quanto longo e coberto com muitas microcerdas. Asas anteriores aproximadamente três vezes mais longas que largas, ápice arredondado, venação distinta e reticulada no terço apical; finamente pontuadas e cobertas de finas e curtas microcerdas.

Pernas, normais; fêmures posteriores cilíndricos, com um achatamento no lado interno, com um espinho apical; tíbias posteriores com dois espinhos, o basal mais curto; ápice com quinze espinhos dispostos em duas fileiras em arranjo semiregular (Fig. 3); tarsos posteriores densamente pilosos, com tarsômero basal de comprimento igual à soma dos dois distais,
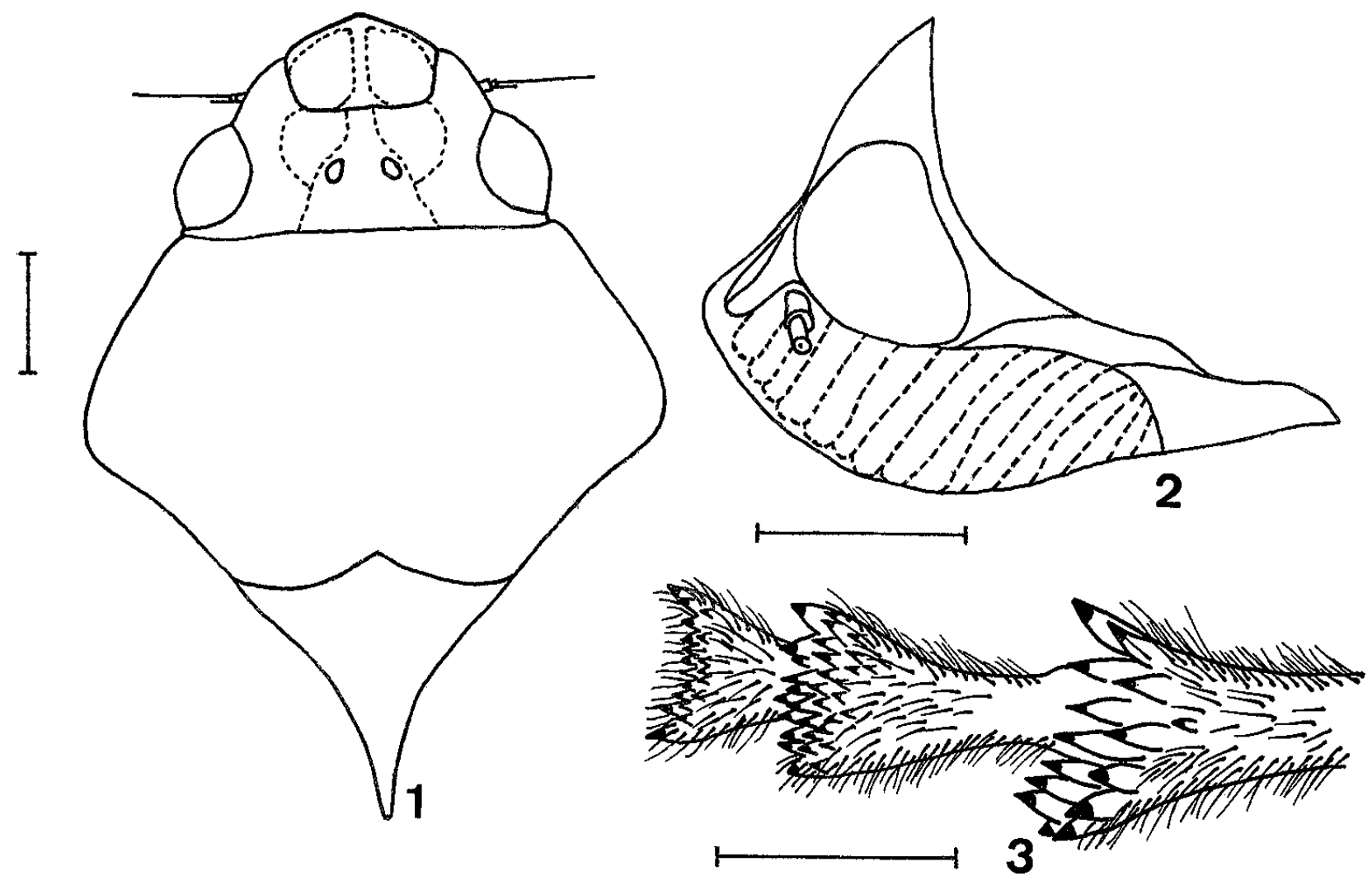

Figs. 1-3. Kanaima dubia sp. nov. 1, cabeça, pronoto e escutelo, vista dorsal; 2, cabeça, vista lateral; 3, ápice da tíbia, $1^{\circ}$ e $2^{\circ}$ tarsômeros da perna posterior; escala $=1 \mathrm{~mm}$. 

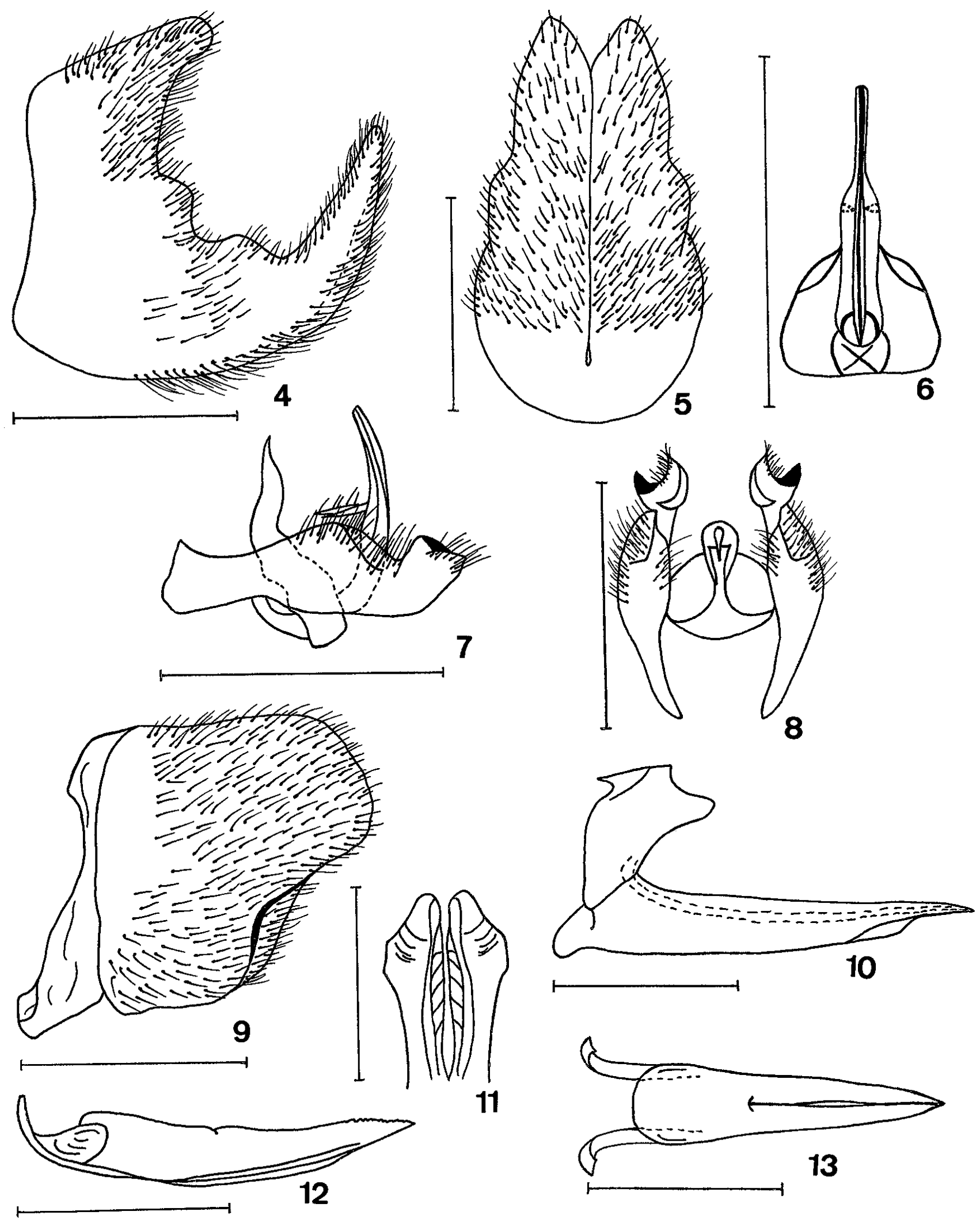

Figs. 4-13. Kanaima dubia sp. nov. 4- 8. Genitália do macho. 4, pigóforo, vista lateral; 5, placa subgenital, vista ventral; 6, edeago, vista posterior; 7, edeago e estilo, vista lateral; 8, edeago e estilos, vista dorsal. Figs. 9 -13. Genitália da fêmea. 9, pigóforo, vista lateral; 10, $1^{\underline{a}}$ valva e valvífero do ovipositor, vista lateral; 11, base da $1^{\underline{a}}$ valva, vista ventral; 12, $2^{\underline{a}}$ valva do ovipositor, vista lateral; 13, $2^{\underline{a}}$ valva do ovipositor, vista dorsal; escala $=1 \mathrm{~mm}$. 

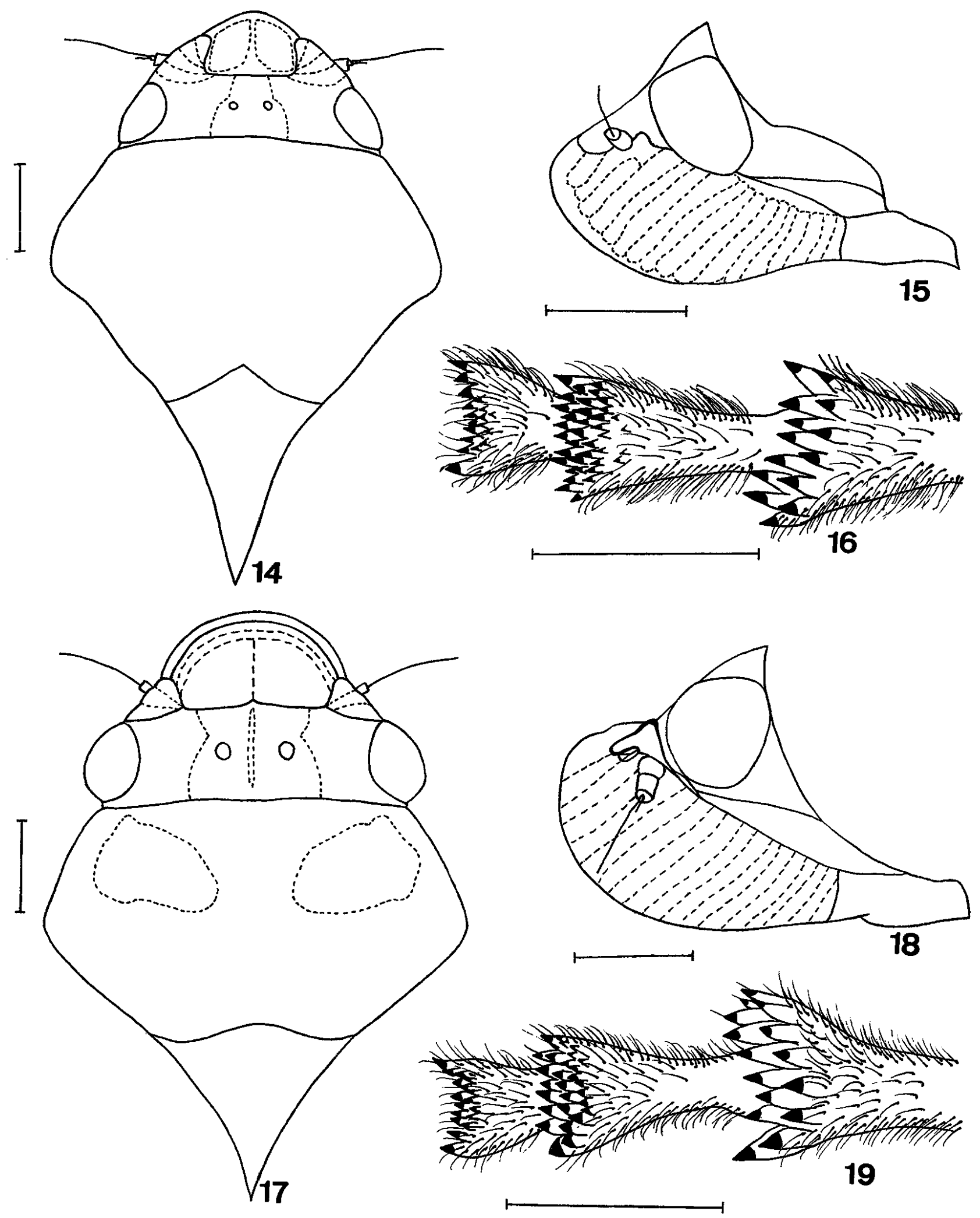

Figs. 14-16. Kanaima fluvialis (Lallemand, 1924). 14, cabeça, pronoto e escutelo, vista dorsal; 15, cabeça, vista lateral; 16, ápice da tíbia, $1^{\circ}$ e $2^{\circ}$ tarsômeros da perna posterior. Figs. 17-19. Kanaima katzensteinii (Berg, 1879). 17, cabeça, pronoto e escutelo, vista dorsal; 18, cabeça, vista lateral; 19, ápice da tíbia, $1^{\circ}$ e $2^{\circ}$ tarsômeros da perna posterior; escala $=1 \mathrm{~mm}$. 

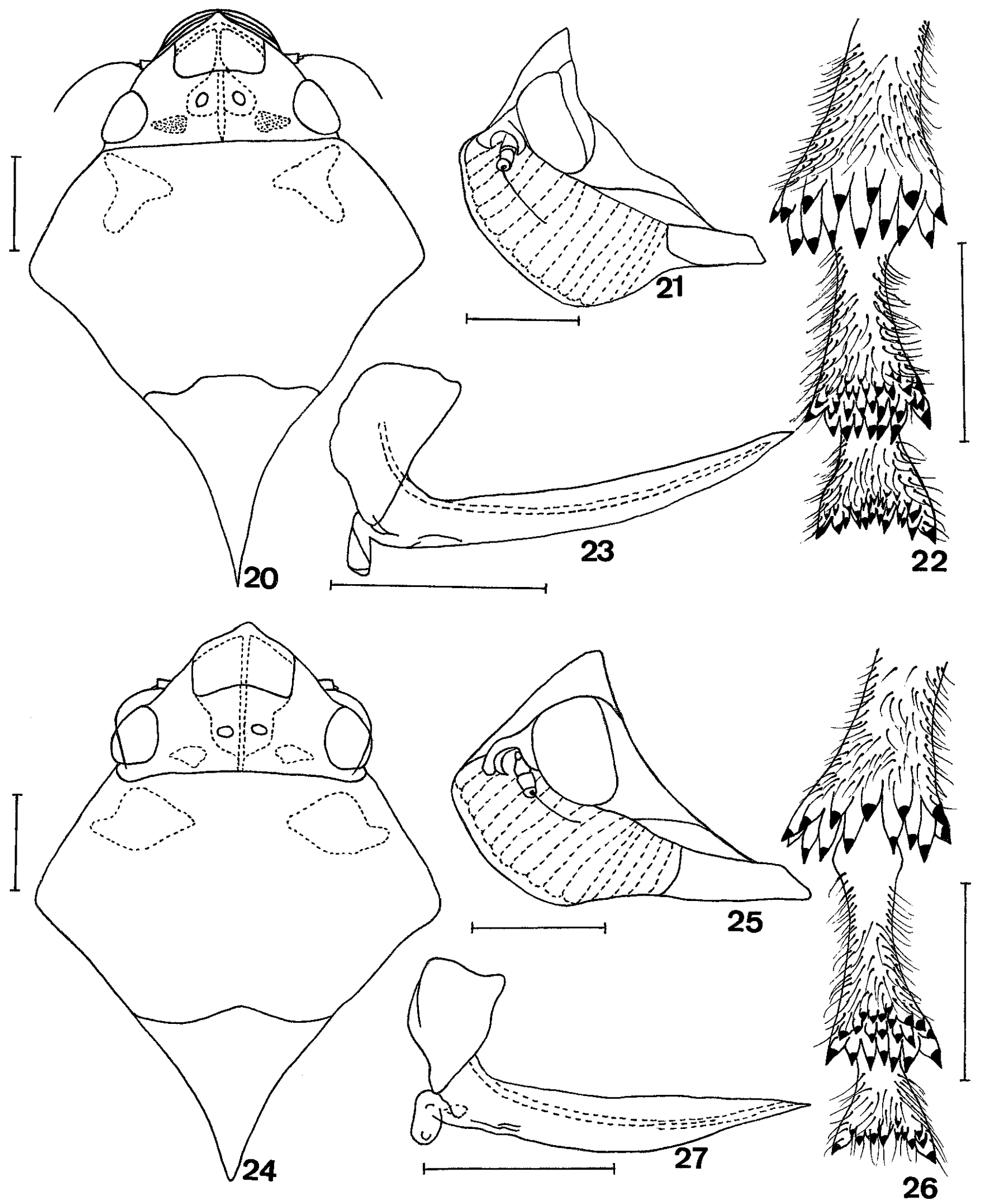

Figs. 20-23. Mahanarva fimbriolata (Stal,1854). 20, cabeça, pronoto e escutelo, vista dorsal; 21, cabeça, vista lateral; 22, ápice da tíbia, $1^{\circ}$ e $2^{\circ}$ tarsômeros da perna posterior; 23, $1^{\varrho}$ valva e valvífero do ovipositor, vista lateral. Figs. 24-27. Mahanarva posticata (Stal,1855). 24, cabeça, pronoto e escutelo, vista dorsal; 25, cabeça, vista lateral; 26, ápice da tíbia, $1^{\circ}$ e $2^{\circ}$ tarsômeros da perna posterior; 27, $1^{\varrho}$ valva e valvífero do ovipositor, vista lateral; escala $=1 \mathrm{~mm}$. 
com trinta e dois espinhos no ápice em três fileiras, arranjados irregularmente (Fig. 3).

Pigóforo, em vista lateral (Fig. 4), com duas projeções láteroposteriores mais ou menos triangulares, voltadas para dentro, com cerdas finas e longas na porção posterior. Placa subgenital coberta por finas e longas microcerdas; em vista lateral (Fig.4), fortemente curvada posteriormente com uma leve projeção triangular ventral; em vista ventral (Fig. 5), bipartida, convexa, apicalmente triangulares e acuminadas. Estilos longos, em vista lateral (Fig.7), com ápice truncado e, em vista dorsal (Fig. 8), com ápice em forma de meia-lua. Edeago (Figs. 6-8) longo, subcilíndrico, levemente curvo, com a base alargada e ligada aos estilos; ápice afilado, com um par de processos pontiagudos, curtos, na posição mediana voltados anteriormente.

Fêmea. Pigóforo, em vista lateral (Fig. 9), tão largo quanto longo, com a margem posterior truncada, com finas e longas microcerdas, em quase toda a sua superfície. Primeiro par de valvas do ovipositor (Figs. 10 e 11), em vista lateral, alongado, de base larga com uma projeção saliente em forma de "calcanhar", e afinando-se para a extremidade apical, com o ápice pontiagudo; primeiro valvífero de forma triangular, parcialmente fundido e perpendicular à base da primeira valva (Fig. 10). Segundo par de valvas do ovipositor, em vista lateral (Fig. 12), com base larga e ápice acuminado, a margem dorsal com uma pronunciada reentrância no ponto mediano e com a porção mais apical serrilhada; em vista dorsal (Fig. 13), fundidas do terço basal até a região mediana, formando uma base larga e afilada para a extremidade apical, com o ápice pontiagudo. Terceiro par de valvas, em vista lateral, de aproximadamente mesmo comprimento do primeiro par de valvas, formando uma espécie de bainha que cobre os dois primeiros pares de valvas, na margem ventral, tendo a mesma estrutura do pigóforo.

Coloração. No aspecto geral, castanho-avermelhada; cabeça, pronoto e escutelo, castanhos e asas anteriores castanho-avermelhadas com duas estrias longitudinais pretas (holótipo), podendo ser contínuas, isto é, formando uma única estria ou estar ausente (parátipos).

Comentários. A nova espécie é mais relacionada a Kanaima fluvialis. Difere de Kanaima katzensteinii, principalmente, na forma da cabeça. Tanto $K$. dubia sp. nov., quanto $K$. fluvialis apresentam uma nítida carena na margem anterior entre o tilo e a face (Figs. 1 e 14), e uma na fronte, em vista lateral, que se estende até a metade desta região (Figs. 2 e 15), não visíveis em K. katzensteinii (Figs. 17 e 18), a qual possui a fronte fortemente abaulada. No entanto, esta carena da fronte não é semelhante àquela encontrada em Mahanarva fimbriolata (Fig. 21) e $M$. posticata (Fig. 25), a qual estende-se até o terço apical desta região. Ambas espécies de Mahanarva, assim como K. dubia e $K$. fluvialis, apresentam uma angulação na margem anterior, em vista lateral (Figs. 2, 15, 21 e 25). Porém, além desta angulação, as espécies de Mahanarva apresentam uma angulação no terço apical da fronte, em vista lateral (Figs. $21 \mathrm{e}$ 25), diferindo das outras três espécies que apresentam o perfil da fronte contínuo com o clípeo (Figs. 2, 15 e 18). Outra estrutura analisada e citada pelos autores que realizaram revisões, principalmente FenNAH $(1968,1979)$, é a espinulação dos segundos tarsômeros dos tarsos das pernas posteriores (Figs. $3,16,19,22$ e 26), onde não houve possibilidade de definir um padrão para os gêneros. As genitálias dos machos são semelhantes, principalmente quanto ao padrão do edeago, diferindo na forma dos estilos. Esta última estrutura parece ser autapomórfica, isto é, ocorrem variações interespecíficas, não apresentando um padrão genérico nas espécies analisadas. Difere também, com relação às valvas do ovipositor que, nas duas espécies de Mahanarva a base das primeiras valvas apresenta uma projeção digitiforme (Figs. 23 e 27), a qual FENNAH (1968) já havia caracterizado como sendo diagnóstica deste gênero.

A proposta de enquadrar a espécie nova em Kanaima é pela proximidade com $K$. fluvialis. No entanto, estas duas espécies apresentam características semelhantes a algumas espécies de Mahanarva, indicando a necessidade de uma revisão destes dois gêneros.

Etimologia. O nome da nova espécie é em razão do problema em enquadrá-la em Kanaima ou Mahanarva.

\section{REFERÊNCIAS}

Berg, C. 1879. Hemiptera Argentina. Anales de la Sociedad Científica Argentina 8: 209-226.

CAvichioli, R. R. \& A. M. SAKakibara. 1988. Espécies brasileiras de Balacha Melichar, 1926 (Homoptera, Cicadellidae). Revista Brasileira de Entomologia 32(2): 279-291.

Distant, W. L. 1909. Rhynchotal notes XLVI. Annals and Magazine of Natural History 3(12): 187-213.

Fennah, R. G. 1968. Revisionary notes on the New World genera of Cercopid froghoppers (Homoptera: Cercopoidea) Bulletin of Entomological Research 58: 165-190.

FennAH, R. G. 1979. Revisionary notes on the New World genera of Cercopid froghoppers (Homoptera: Cercopoidea) II. Bulletin of Entomological Research 69: 267-273.

Hamilton, K. G. A. 1981. Morphology and evolution of the rhynchotan head (Insecta, Hemiptera, Homoptera). The Canadian Entomologist 113: 953-974.

Lallemand, V. 1924. Homoptères Nouveaux de la Collection du Muséum National de Paris e de la mienne. Bulletin du Muséum National d'Histoire Naturelle 30: 378-385.

Nielson, M. W. 1965. A revision of the genus Cuerna (Homoptera, Cicadellidae) Technical Bulletin. United States Department of Agriculture 1318: 1-48.

Snodgrass, R. E. 1935. Principles of the insect morphology. New York, Mc Graw-Hill, 667 pp.

WALKER, F. 1851. List of the specimens of Homopterous insects in the collection of the British Museum. Part III. London, p 637-907. 